\title{
The Flow Experience of MOOC Learners and Their Influencing Factors
}

\author{
Hu Zhihai \\ School of Educational Science \\ Huangshan University \\ Huangshan, China \\ email: hzhls@hsu.edu.cn
}

\author{
Lu Jun \\ School of Educational Science \\ Huangshan University \\ Huangshan, China \\ email:1270180122@qq.com
}

\begin{abstract}
From the perspective of the experience of the learners of the MOOC, it provides a reference for the development of the MOOC and the improvement of the learning effect. Through the questionnaire survey, the differences in the experience of the learners in the MOOC are studied. The results show that there are significant differences in the experience of the learners of different classes of MOOCs. The enlightenment of the learners and the public learners is in the flow of experience. There are significant differences in the state dimension, and the learning attitude and learning effect of the high heart flow experience group are significantly higher than the low heart flow experience group. The gender, personal attitude and learning effect of the learners are the important influencing factors of the learner's experience.
\end{abstract}

Keywords-MOOC, heart flow experience, college students, online education

\section{INTRODUCTION}

MOOC, referred to as "massive open online course", means a large open online learning course, which is a new form of network distance education. As a large-scale online open course, MOOCs are characterized by openness, participation and decentralization [1]; on the one hand, these advantages can partially solve the problem of uneven distribution of resources in colleges and universities, and on the other hand, give learners access to professional knowledge. Channels and simple and quick ways to learn. However, MOOC also has its own drawbacks. Although most learners have clear learning motivations, due to the uneven learning foundation, some students can't persist in learning for a long time, and there is a phenomenon of high registration rate and low pass rate [2]. It can be seen that the scope of influence and future prospects of MOOCs are influenced by learners' willingness to learn and attitudes [3]. Therefore, many scholars at home and abroad have begun to pay attention to the study of the learning process of the MOOC, such as learning attitude, personal motivation, and the persistence of learning in the classroom. The learner's experience is very worth exploring.

The flow of experience is first proposed by Csikszentmihalyi in his book The Flow of Life. He believes that as long as one concentrates on his own attention and does one thing, it will produce a flow of heart. He defines the experience of heart flow as a feeling of completely betting personal emotions on certain activities [4]; and emphasizes that there is a high degree of continuous excitement and emotional fullness when the flow of mind is generated. Csikszentmihalyi divides the heart flow experience into nine dimensions, such as clear goals.
Among them, the first three dimensions are considered as the conditional factors for the occurrence of the heart flow experience [4]. The heartbeat experience will stimulate the change of personal attitudes and motivations into a positive direction, allowing individuals to better immerse themselves and contribute to the focus of learning.

Since the introduction of the theory of heart flow experience, the experience of heart flow and its extended application research are extensive. According to the content of the research, it can be roughly divided into two categories: one class of research experience and its theory [5]; the second type is The experience of heart flow is combined with other factors, such as network, sales, education industry, etc., to enhance the experience of individuals in games and learning [6]; combine the experience of heart flow and online learning to study online learners online The persistence attitude of learning is influenced by the influence and function of the heart flow experience, and whether the heartbeat experience really affects the attitude and motivation of online learners.

This study combines the theory of heart flow experience with the study of MOOCs to explore the experience of the learners and their influencing factors. Get information from them to improve the MOOC, improve the learning mechanism, and promote the two-way development of MOOC and MOOC learners.

\section{METHODS}

\section{A. Research object}

The study selected 231 students from Huangshan College and collected 205 valid questionnaires. The questionnaire efficiency was 89\%. There are 97 boys, 108 girls, 112 in the motto group and 93 in the public class.

\section{B. Research tools}

The research questionnaire consisted of Ye Jinhui's youth learning immersion experience questionnaire and the selection of Pan Lijia's personal attitude and learning effect.

The Youth Learning Immersion Experience Questionnaire has a total of 52 questions, including the balance of tasks and skills, the integration of consciousness and action, purpose and feedback, concentration, self-esteem, control, and enjoyment experience [7]. The questionnaire was scored by "very non-conformity" to "very consistent" five-point method. The higher the score of the questionnaire, the higher the individual's immersion experience. The cloned Bach a coefficient of the 
questionnaire is greater than 0.80 , and has high internal consistency and high validity.

The personal attitude questionnaire has a total of 15 questions, Cronbach's alpha value is greater than 0.7 , with good reliability and validity [8]. The learning effect questionnaire has a total of 16 questions, with a KMO value of 0.936 and a Cronbach's alpha value of 0.931 , which has a high reliability and validity.

Data were statistically analyzed using SPSS 18.0.

\section{RESULTS AND ANALYSIS}

\section{A. Difference comparison}

Compare the three dimensions of the individual attitude, learning effect and heart flow experience of the learners and the public class learners, as shown in Table I.

TABLE I. COMPARISON OF DESCRIPTIONS BETWEEN MOOC AND PUBLIC CLASSES

\begin{tabular}{cccc}
\hline & & Mean & Std. Deviation \\
\hline \multirow{3}{*}{$\begin{array}{c}\text { Mooc } \\
\text { Group }\end{array}$} & $\begin{array}{c}\text { Personal } \\
\text { learning result }\end{array}$ & 47.64 & 9.896 \\
& flow experience & 152.54 & 11.975 \\
& Personal & 49.86 & 33.193 \\
public & attitude & 5.525 \\
classes & learning result & 55.55 & 10.266 \\
& flow experience & 149.77 & 29.020 \\
\hline
\end{tabular}

It is concluded that the personal attitudes and learning effects of the MOOC and the public classes are different. The public curriculum group is more stable in the two dimensions than the Mu group; in the experience of the heart, the experience of the group is higher than that of the public group. .

There is a significant difference between the MOOC learners and the public class learners in the flow experience, personal attitudes and learning effects. This study uses the $t$ test to compare, as shown in Table II and Table III (1 in the table represents the MOU group; 2 is on behalf of the public class)

TABLE II. COMPARISON OF THE DIFFERENCE BETWEEN THE TWO GROUPS

\begin{tabular}{ccccc}
\hline & Mean & SD & t & Sig. (2-tailed) \\
\hline flow experience & 3.677 & 46.130 & .769 & .444 \\
Personal attitude & -1.753 & 12.843 & -1.316 & .191 \\
Learning result & -1.710 & 16.127 & -1.022 & .309 \\
\hline
\end{tabular}

TABLE III. COMPARISON OF THE SEVEN DIMENSIONS OF THE TWO GROUPS OF FLOW

\begin{tabular}{ccccc}
\hline & Mean & SD & $\mathrm{t}$ & Sig \\
\hline $\begin{array}{c}\text { Balance of tasks and } \\
\text { skills }\end{array}$ & .011 & .131 & .227 & .828 \\
$\begin{array}{c}\text { Integration of } \\
\text { consciousness and } \\
\quad \text { action }\end{array}$ & .107 & .164 & 1.847 & .107 \\
$\begin{array}{c}\text { Purpose and } \\
\text { feedback }\end{array}$ & -.029 & .138 & -.515 & .629 \\
$\quad \begin{array}{l}\text { Attention } \\
\text { Forgetting State }\end{array}$ & .107 & .238 & 1.353 & .213 \\
$\quad$ Control Sense & .067 & .161 & 2.736 & .034 \\
Enjoy the experience & -.063 & .192 & -.862 & .422 \\
\hline
\end{tabular}

The results shown indicate that there is no significant difference in the three dimensions of the heart flow experience, personal attitude and heart flow effect of the MTU group learners and the public class group learners; the two groups have significant differences in the evanescent state of the heart flow experience, p value Less than 0.05 , the class learners have a better experience state in the dimension of the self-study state than the public class learners. There were no significant differences between the two groups in the remaining dimensions.

Due to the different behaviors and thinking of different genders, the experience, learning effect and personal attitude of the learners may cause differences in learners of different genders, and make three dimensions of t test.

TABLE IV. GENDER DIFFERENCES IN LEARNERS

\begin{tabular}{ccccc}
\hline & MD & SD & $t$ & Sig \\
\hline Personal attitude & -.477 & 1.931 & -.247 & .805 \\
Learning effect & 4.177 & 2.303 & 1.814 & .072 \\
Flow Experience & 16.042 & 6.295 & 2.548 & .012 \\
\hline
\end{tabular}

As shown in Table IV, there are significant gender differences in the experience of the students in the MOOC; there is no significant gender difference in personal attitudes and learning effects.

The $27 \%$ of the students in the top of the flow experience score were selected as high scores, and 27\% of the social anxiety scores were low. The differences between the two groups in personal attitudes and learning effects were compared.

TABLE V. COMPARISON OF HIGH AND LOW GROUPS

\begin{tabular}{ccccc}
\hline & MD & SD & $t$ & Sig \\
\hline Flow & 81.033 & 4.503 & 17.995 & .000 \\
Personal attitude & 10.133 & 1.920 & 5.278 & .000 \\
Learning effect & 14.867 & 2.728 & 5.450 & .000
\end{tabular}

As shown in Table V, the comparison between the heart flow experience, personal attitude and learning effect is $\mathrm{p}<0.01$; it indicates that the heart flow experience, personal attitude and learning effect corresponding to the high group experience of the learner's heart flow experience are significant. Higher than low grouping.

\section{B. Relevance verification}

This study focuses on the influencing factors of the heartbeat experience of the learners in this class. This time, gender, personal attitudes and learning effects are verified as three-dimensional in the heart flow experience.

TABLE VI. FACTORS RELATED TO THE EXPERIENCE OF THE LEARNERS IN THE MOOC

\begin{tabular}{ccccc}
\hline & $\begin{array}{c}\text { flow } \\
\text { experience }\end{array}$ & gender & $\begin{array}{c}\text { personal } \\
\text { attitude }\end{array}$ & $\begin{array}{c}\text { learning } \\
\text { effect }\end{array}$ \\
\hline flow experience & & $-.236^{*}$ & $.447^{* *}$ & $.551^{* *}$ \\
gender & $-.236^{*}$ & & .024 & -.170 \\
personal attitude & $.447^{* *}$ & .024 & & $.699^{* *}$ \\
learning effect & $.551^{* *}$ & -.170 & $.699^{* *}$ & \\
\hline$* . \mathrm{p}<0.05,{ }^{* *} . \mathrm{p}<0.01$ & & &
\end{tabular}

The data processing was analyzed by Pearson correlation method; the significance $\mathrm{p}$ value was less than 
0.05 , and it was considered that gender, personal attitude and learning effect had significant influence on the experience of heart flow. Gender, personal attitude and learning effect were the experience of the learners. High and low factors.

\section{DISCUSSION}

The public courses that adopt the traditional teaching method mainly rely on the supervision of the classroom teachers, and the courses are studied at fixed locations at a fixed time. The MOOC class has realized the transformation of the learning style, from the past "receiving learning" to the student independent cooperation "exploratory learning"[9] , which is more likely to generate a heart flow experience in the video distance learning and online cooperative learning methods. It can be seen from the statistical results that the learners in the dimension of self-esteem state have a better state than the learners in the public class, and there are significant differences.

Because girls' ability to learn and be more conscious than boys, and girls' attitude towards learning is better than boys [10], the experience of heart flow is significantly different in gender. The level of experience of the heart flow is related to the individual's motivation to learn. In the case of high individual motivation, a positive attitude towards the learning of the class will be generated, which will lead to different experiences of the heart flow; and the experience of learning will affect the learner in the next stage. At the stage of learning input and learning status, learners with high experience of heart flow are more willing to follow the learning [6], and actively explore, so that the individual attitude is more active in the next stage of learning. In terms of learning effect, the learner's experience of heart flow will directly affect the learner's acquisition of course knowledge. Learners with high experience will have more attention and input, while learners with low experience will have less experience. On the contrary, there is a significant difference between the two. Gender, personal attitude and learning effect are important factors influencing the experience of the learners.

According to the results of this study, the following suggestions are proposed to the MOOC platform: First, we should pay attention to the learner's heart flow experience and strengthen the human-computer interaction of the platform. Secondly, the online education platform course can implement a certain charging system, so that learners pay more attention to the MOOC. In addition, the platform can give learners a certain reward or implement a voucher system to ensure the persistence of the learners of the MOOC and improve the learning effect.

There are certain limitations in this study. In the process of testing the questionnaire, the form of the MOOC should be diverse in terms of the measured objects. Although the course of Huizhou Culture in the online platform course of
Huangshan College is in the form of MOOC, However, in terms of learners, the selection of credits will affect the learner's attitude and experience, and the study will be all college students, resulting in a single age and cultural quality of the subjects, affecting the accuracy of the research. And validity. In the subsequent research, the research object of the learner's heart flow experience will be reduced to the above additional variables to provide a better basis for research.

\section{CONCLUSION}

There are significant gender differences in the experience of the learners of the MOOCs. The gender, personal attitudes and learning effects of the learners are important factors influencing the learners' experience, and the MOOCs are more traditional in the public courses. There are certain advantages in the experience.

\section{ACKNOWLEDGEMENT}

This research was financially supported by the Key research project of humanities and social sciences of Anhui Provincial Department of Education (SK2016A0879). \&Horizontal scientific research project of Huangshan University.

\section{REFERENCES}

[1] Chen Jirong, "Review on the Latest Development of Foreign Mutu Studies” Foreign Language Teaching and Research, vol.48, pp.118-127, January,2016.

[2] Bai Qian, Zhao Li, Zhang Shuyu., "The Status Quo and Reflection of Motivation Learning__ Based on the Influence Factors of Negative Motivation of Learners in China” Modern Educational Technology, vol.13, pp.65-71, December,2016.

[3] Yan Xin, Lu Honglei. "Research on the Influencing Factors of Learners' Adoption of MOOC: Based on the User Survey of "School Online” of Tsinghua University” Modern Distance Education, vol.31, pp.3-8,May,2014

[4] Mihari Cheekson Mihalai, Chen Xiujuan translation The flow of life, Beijing, CITIC Publishing House, 2009 , pp. 42-46.

[5] Ren Jun, Shi Jing, Ma Tianyu. “Overview of Flow Research” Advances in Psychological Science, vol.17, pp. 210-217, January,2009.

[6] Wang Wei, Shi Ruihan, Li Xiaona. "Research on the Influencing Factors of Online Learning Sustained Willingness Based on Heart Flow Experience” China Distance Education, vol.37, pp.17-23+79, May,2017.

[7] Ye Jinhui. Research on Adolescent Learning Immersion Experience, Jiangxi Normal University, 2013.

[8] Pan Lijia. Research on the relationship between MOOC design, learner participation and learning performance. Zhejiang University, 2015.

[9] Wang Qiuyue,“The Essence and Application of "Mu Class" and "Flip Class" and Its Application" Shanghai Education Research, vol.33, pp.15-18.August,2014.

[10] Liu Lu,Guo Dongsheng,“Analysis of Gender Differences in College Students' Deep Learning” Journal of China Women's University, vol.28, pp.23-27, April,2016. 